\title{
AIRSIDE CAPACITY ANALYSIS AND EVALUATION OF İSTANBUL ATATÜRK AIRPORT USING FAST-TIME SIMULATIONS
}

\author{
Mustafa ÖZDEMIR ${ }^{1, *}$, Cem ÇETEK ${ }^{1}$, Öznur USANMAZ ${ }^{1}$ \\ ${ }^{1}$ Department of Air Traffic Control, Faculty of Aeronautics and Astronautics, Anadolu University, Eskişehir, Turkey
}

\begin{abstract}
The demand for air transportation increases rapidly each year and introduces serious problems such as system-wide delays and congestions in air traffic operations. Airports, one of the most critical points of the air transportation system, are affected most by these problems. One of the most effective approach to reduce delays and congestions is to improve existing airside capacity of airports through the enhancement of taxiway network around runways. This study investigates the impacts of various rapid-exit and end-around taxiway combinations on capacity and delays for İstanbul Atatürk Airport. Four different runway configurations are analyzed using fast-time simulations for the existing (baseline) and improved (alternative) taxiway network of the airport. The results show that end-around taxiways can decrease departure taxi times up to $52 \%$ and rapid-exit taxiways reduce arrival runway occupancy time by $10.6 \%$. Besides, implementations of end-around taxiways can improve runway capacity especially when the airport experiences intense arriving traffic while rapid-exit taxiways improves runway utilization for arrivals.
\end{abstract}

Keywords: Air traffic flow and capacity management, Fast-time simulation, End-around taxiway, Rapid-exit taxiway

\section{INTRODUCTION}

Airports are the most important aspects of the air transport system because they are the starting and ending points of air transportation. Nowadays, however, especially major airports may have inadequate capacity to meet the increasing demand. An airport's capacity can be defined as the amount of traffic that can be serviced within a given period of time whereas demand is the total number of aircraft waiting for service within the same duration. When this increased demand exceeds capacity, congestion and delays occur at airports and this leads to a disruption of the traffic flow in the other parts of the air traffic system.

The capacity of an airport depends on the capacities of its landside and airside components. The landside components include the elements directly related to passenger access of aircraft, such as terminal buildings and ground transportation systems to the airport. The airside components, on the other hand, comprise runway systems, taxiway networks and apron areas that are directly related to aircraft operations. Although landside and airside operations are interdependent, the capacity of runway systems usually restricts the total capacity of airports [1]. Runway system capacity is the maximum number of aircraft operations that can be served by a specified runway combination $[2,3]$. It depends on many factors such as the operation standards applied to aircraft, the aircraft type and performance, arrival-departure ratio, weather conditions, runway configuration, location and the number of taxiways and gates etc. [4-6].

The most effective approach to increase runway system capacity is to achieve a more productive utilization of the existing systems and to find more appropriate strategies for potential improvements through the investigation of gates, taxiways and maneuvering areas [7, 8]. The use of fast-time simulations is a commonly employed technique to analyze the complex and dynamic behavior of traffic flow and to evaluate impacts of new operational approaches and possible improvements to the 
infrastructure of runway systems [9]. They have been used in numerous airspace and/or airport studies due to these advantages [10]. In this study, SIMMOD (the Airport and Airspace Simulation Model), a discrete-event fast-time simulation tool, is used. There are a number of studies carried out with SIMMOD in literature. Gao et al. and Kleinman et al. used a simultaneous perturbation stochastic approximation (SPSA) optimization method to reduce air traffic delays and tested the results with SIMMOD [11, 12]. Peng et al. used Agent Unified Modeling Language (AUML) to illustrate aircraft arrival and departure procedures for a runway capacity analysis and evaluation in parallel runway operations, and then they tested the model with ARENA and SIMMOD simulation tools [13]. Simaiakis and Balakrishnan assessed the effects of congestion at major airports on taxi times, fuel consumption, and emissions through SIMMOD [14]. In the study carried out by Bubalo and Daduna, the maximum practical capacity of Berlin-Brandenburg International Airport during independent parallel runway operations was investigated through simulation, depending on the increasing number of traffic and different traffic mix [6]. In another study by Lee and Balakrishnan, the impact of uncertainties such as taxi speed, runway exit times, and pushback time at Detroit International Airport was investigated by means of fast-time simulation. As a result of the simulation, it was emphasized that ground delay increases with an increase in uncertainty level in most scenarios [15].

\subsection{Problem Definition}

İstanbul Atatürk Airport (LTBA) is the busiest airport in terms of flight operations in Turkey. In January 2016, 35,212 commercial flights were carried out, and the number of operations increased by $3 \%$ compared to January 2015. By the end of 2015, LTBA has become Europe's third busiest airport based on total passenger traffic [16]. This demand has been increasing each year and led to delays and congestion at the airport, and consequentially a loss of time and revenue. According to EUROCONTROL's report called "Network Monthly Operations Report" which was published in June 2016, among European airports, LTBA is ranked third in terms of airports facing the most capacity delays [17].

A number of precautions has been taken to eliminate these delays and congestion problems at LTBA. One of them is the construction of a third airport in İstanbul. According to the schedule, the first phase of the airport is planned to be completed in 2018, and all stages are expected to be completed by 2028 $[16,18]$. When completed, it is expected to reduce traffic congestion at LTBA, but it will take years for the completion of this project. Therefore, it is necessary to take some precautions in the short term to solve congestion and delay problems.

Consequently, building new airports is a long-term solution but there are alternative ways to solve congestion problems and improve capacity at airports in relatively shorter terms. The use of endaround taxiways (EATs) and rapid-exit taxiways (RETs) can be considered as short-term solutions for such problems. These solutions can provide efficient results in terms of improving the airport capacity and reducing the number of runway crossings. Accordingly, this study proposes two EATs and RETs for LTBA, and investigates their effects on capacity, delay, taxi and runway occupancy times.

\subsection{End-Around Taxiways}

EATs are constructed around a runway. They allow an aircraft to taxi unrestrictedly to the terminal building or to the runway rather than having aircraft hold and cross an active runway. Although the taxi distance increases compared to conventional taxiways, the overall taxi time decreases as the aircraft do not have to wait to cross an active runway [19]. Besides, they can reduce potential runway incursions, frequency occupation, and fuel burn and emissions due to non-stop taxi [20].

Jadhav et al. proposed the use of EATs in Chicago's O'Hare airport, and they tested various scenarios using ARENA. They state that the use of EATs will reduce the number of runway incursions [19]. 
Uday et al. investigated environmental effects of EAT operations. According to their results, EATs reduce average fuel burn and emissions of aircraft compared to conventional taxiways [21]. Le and Marais developed a decision support model for effective use of EATs and conventional taxiways in terms of environmental perspective. They stated that an EAT provides potential time and fuel savings when traffic demand is high while it increases taxi time when traffic demand is low [22].

Although EAT concept has been studied for several major airports with parallel runway configurations in the U.S., its performance has not been evaluated for airport with complex open-V runway configuration such as LTBA. This study could provide a good insight to the airport with similar runway configuration and demand characteristics, especially in Europe and other developing countries.

An aircraft on the ground can taxi independently of arrival aircraft through an end-around procedure. However, when designing EATs, certain conditions must be fulfilled to prevent aircraft from penetrating departure and approach surface. EAT must be entirely outside of the runway safety area, and all instrument landing system (ILS) critical areas. Therefore, the distance constraints shown in Figure 1 must be provided. These distances are valid for the cases where the stop end of runway elevation is equal to the EAT elevation [23]. In the simulation model, the EATs were designed based on the runway departure surface dimensions and the aircraft tail height.

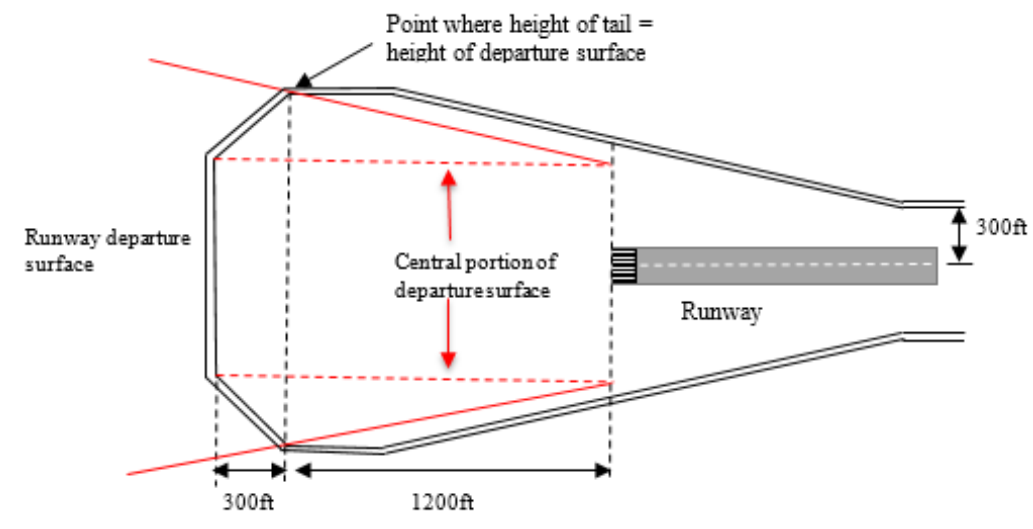

Figure 1. Construction of an EAT around a runway [23]

\subsubsection{Rapid-exit taxiways}

RETs are taxiways that allow a landing aircraft to vacate the runway earlier and at a higher speed rather than leaving the runway in the end. Thus, the runway occupancy time can be decreased and more efficient use of the runway can be achieved [24]. Cetek et al. proposed a new RET in LTBA on the left side of runway 05 , and they concluded that some improvements were achieved in the arrival runway occupancy time, the departure and arrival taxi delays, the departure queue delay and the maximum departure queue length in the examined runway configurations [25]. This study expands this analysis for more complex operational scenarios which include two additional RETs for runway 05 and 23.

\section{MATERIALS AND METHODS}

\subsection{Simulation Model}

LTBA has three runways which are open-V shaped, and named 35R/17L, 35L/17R and 05/23. Runway 35R/17L and 35L/17R are not used simultaneously. The preferential runway system (PRS) for LTBA is RWY 05 for landing, and RWY 35R/L for departure. The PRS refers to the optimal runway configuration that can be used for aircraft landing and take-off considering aircraft 
performance, wind speed and direction [26].

The model of LTBA is built up using SIMMOD by entering the actual airport ground coordinates as shown in Figure 2. The ground structures of the airport, including runways, taxiways, and gates, are designed using Aeronautical Information Publication (AIP) data from 2017.

The infrastructure changes given in Figure 2(b) are developed to use the apron Y, which is located on the right side of the runway 05, more efficiently. Two EATs are proposed at the end of the runway and at the beginning of the runway to prevent departure aircraft at apron Y from crossing the runway 05 . In the simulation, without an EAT aircraft follow the taxiways numbered as 1 and 2 shown in Figure 2(a) to reach runway 35R. In this case, aircraft are required to cross runway 05 . The reason for the use of numbered taxiways is that these taxiways are the shortest way connecting apron $\mathrm{Y}$ and runway 35R. Even if these taxiways are not preferred and instead taxiway 3 is used, it is not possible for aircraft to taxi independently from arrival aircraft because it is not far enough from the beginning of the runway 05 (the distance between the taxiway 3 and the beginning of runway 05 is about $600 \mathrm{ft}$ ).

In order for an aircraft to cross an active runway, another aircraft approaching for landing should not be closer than a specified distance from the runway threshold (this distance may change in operational conditions, in the study it is accepted as 2NM considering controller-pilot reaction time). Otherwise, the aircraft on the ground must wait for the arrival aircraft to land. This procedure is provided by controller-pilot communication, and it requires specific clearance from ATC.

The other proposal is a new RET for runway 05 and 23. If the aircraft landing on runway 05 are required to taxi to a gate at apron $\mathrm{Y}$, some of them have to vacate the runway in the end because there is no RETs close to the end of the runway. Adding a RET on runway 05 and 23 may reduce the runway occupancy time.

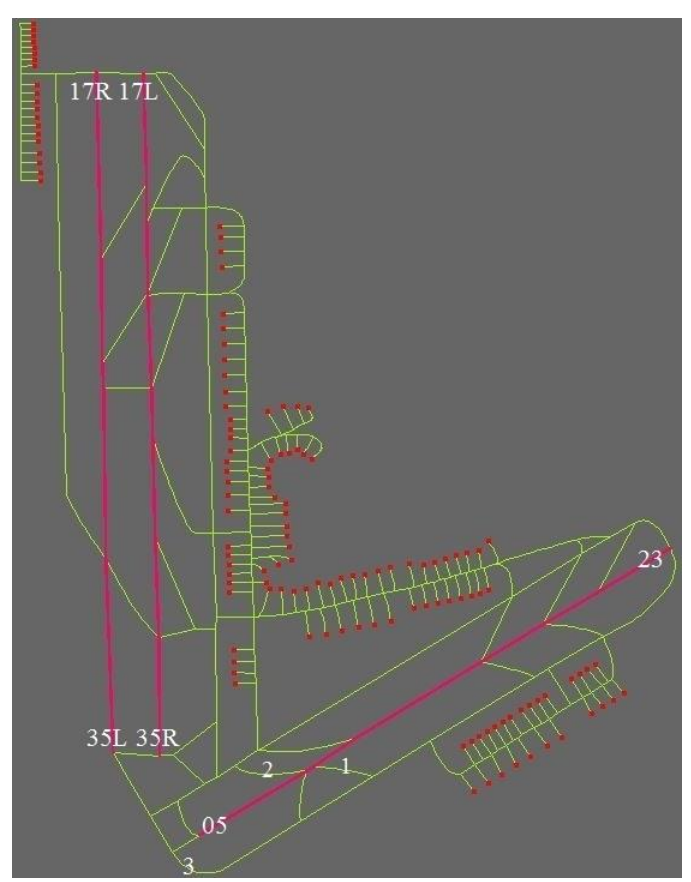

(a)

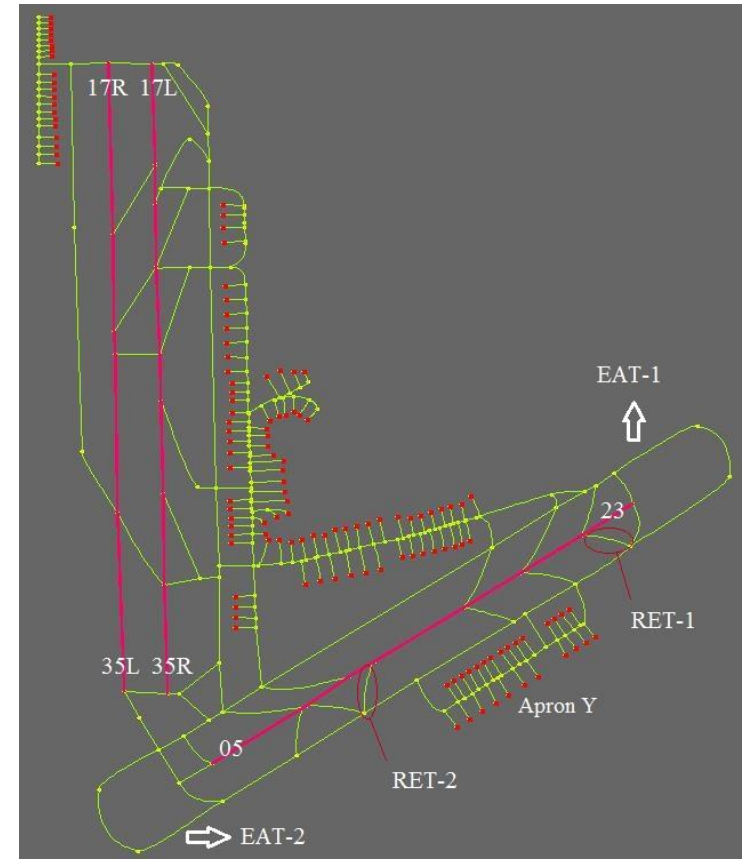

(b)

Figure 2. (a) SIMMOD airfield model for LTBA; (b) SIMMOD airfield model for LTBA including proposed infrastructures changes 
In the simulation, a total number of 200 aircraft based on peak-hour traffic data including 102 take-off and 98 landing operations are used. Aircraft category affects traffic flow through airspace and in airports due to wake turbulence. Therefore, the distribution of aircraft categories is determined as $2 \%$ light, $88 \%$ medium and $8 \%$ heavy considering the real data.

Using the Base of Aircraft Database (BADA) [27], the approach and departure airspeeds and landing and take-off roll distances of each aircraft category are estimated as the weighted average of aircraft available in the air traffic data. Corresponding roll distances of each category are defined as random piece-wise linear variables.

\subsection{Scenarios}

RWY 05 for landing and RWY 35R/L for departure configurations are used as the PRS at LTBA. PRS operations allow the use of an aerodrome at maximum capacity. However, the use of the preferential runway configuration is not always possible due to wind direction, air traffic conditions, local meteorological conditions, environmental restrictions, technical infrastructure and noise abatement [26]. Therefore, different runway configurations were created together with the preferential runway configuration.

In the scope of the study, firstly, different runway configurations are investigated in terms of runway system capacity and average delay. In the second step, new RETs and EATs are proposed for runway 05 and 23, and their effects on traffic flows at the airport are analyzed. Table 1 shows the scenarios with runway configurations and proposed improvements. In scenario 1, 05A-35D configuration is examined in terms of capacity and average delay while the effect of EAT-1, EAT-2 and RET-1 shown in Figure $2 \mathrm{~b}$ is examined with scenarios $1 \mathrm{a}, 1 \mathrm{~b}$ and $1 \mathrm{c}$. In the other configurations, only RETs are investigated by comparing them with the baseline scenarios.

Table 1. Base and alternate scenarios

\begin{tabular}{lllll} 
Baseline scenarios & & \multicolumn{3}{l}{ Alternate Scenarios (Proposed improvements) } \\
\hline \multirow{2}{*}{ 05A-35D } & & + EAT-1 & $\rightarrow$ & Scenario 1a \\
\cline { 3 - 5 } & Scenario 1 & + EAT-2 & $\rightarrow$ & Scenario 1b \\
\cline { 3 - 5 } & & + RET-1 & $\rightarrow$ & Scenario 1c \\
\hline 23A-17D & Scenario 2 & + RET-2 & $\rightarrow$ & Scenario 2a \\
\hline 05A-D & Scenario 3 & + RET-1 & $\rightarrow$ & Scenario 3a \\
\hline 23A-D & Scenario 4 & + RET-2 & $\rightarrow$ & Scenario 4a \\
\hline *A: Arrival, D: Departure & & & &
\end{tabular}

The minimum separation between aircraft used in the simulation is shown in Table 2, in terms of time and distance. Numbers marked $*$ are the International Civil Aviation Organization (ICAO) wake turbulence separation values [2]. The others are user-defined values. In the table, only arrival-arrival and departure-departure separations are shown for all scenarios. For scenario 2, 6 nautical miles (NM) separation is used between arrival and departure aircraft due to the intersection of the runway axis. No conflicts were observed during the simulation when using $6 \mathrm{NM}$ of separation. 2NM of separation is used between arrival and departure operations for scenario 3 and scenario 4 since they use the same runway. In addition, the minimum radar separation distance is accepted as $4 \mathrm{NM}$ for arrival aircraft on the same final approach path. 
Özdemir et al. / Anadolu Univ. J. of Sci. and Technology A - Appl. Sci. and Eng. 19 (1) - 2018

Table 2. Minimum separations between aircraft based on time (sec)/distance (NM)

\begin{tabular}{|c|c|c|c|}
\hline \multicolumn{4}{|c|}{ Arrival-Arrival } \\
\hline \multirow[t]{2}{*}{ Leading aircraft } & \multicolumn{2}{|c|}{ Trailing aircraft } & \\
\hline & Heavy & Medium & Light \\
\hline Heavy & $60 / 4$ & $120 * / 5 *$ & $180 * / 6 *$ \\
\hline Medium & $60 / 4$ & $60 / 4$ & $180 * / 5 *$ \\
\hline Light & $60 / 4$ & $60 / 4$ & $60 / 4$ \\
\hline \multicolumn{4}{|c|}{ Departure-Departure } \\
\hline \multirow[t]{2}{*}{ Leading aircraft } & \multicolumn{2}{|c|}{ Trailing aircraft } & \\
\hline & Heavy & Medium & Light \\
\hline Heavy & $60 / 2$ & $120 * / 2$ & $120 * / 2$ \\
\hline Medium & $60 / 2$ & $60 / 2$ & $120 * / 2$ \\
\hline Light & $60 / 2$ & $60 / 2$ & $60 / 2$ \\
\hline
\end{tabular}

\section{RESULTS}

Figure 3 shows the capacity and average delay times for the base scenarios. The maximum capacity and minimum average delay time are obtained for scenario 1, which represents the PRS for LTBA. The lowest capacity is obtained as 35 for scenario 2, which is the opposite configuration of the PRS. For scenario 3 and scenario 4, capacities were obtained as 44 and 43 respectively. The reason for the high average delay for scenario 2 is the separation minimum applied between the landing and departure aircraft due to the intersection of the runway axis. Simulation results show that the aircraft have not been delayed significantly in the PRS, while in the opposite configuration the delay times have reached an unacceptable level.

Even in the case of using a single runway for arrival and departure operations, the capacity is higher than the opposite runway configuration. This indicates that, when necessary, the use of a single runway for both arrival and departure will be more efficient in terms of capacity and delay rather than using the opposite runway configuration. For this reason, in this study, the RETs and EATs have been investigated to increase the capacity of the PRS and for more efficient use of apron Y.

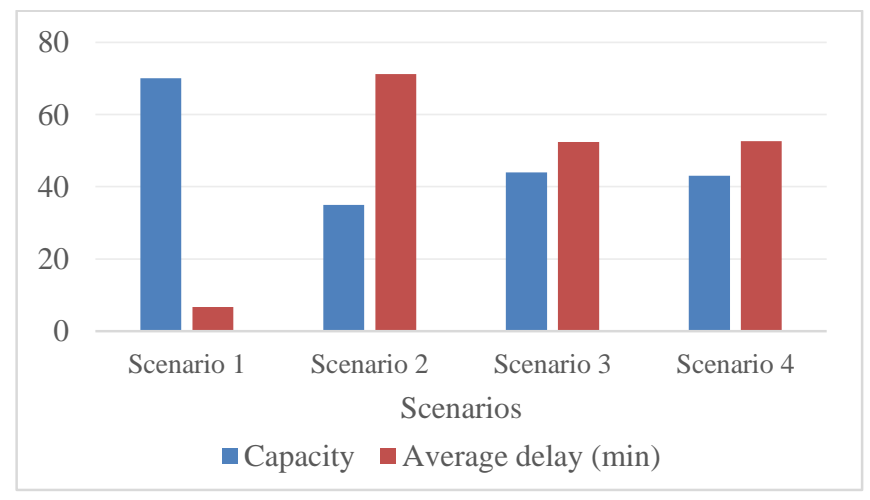

Figure 3. Capacity and average delay times for the baseline scenarios

In 05 landing/35R departure configurations, departure aircraft at apron $\mathrm{Y}$ are required to cross runway 05 in order to taxi to runway $35 \mathrm{R}$. However, in order for the aircraft to pass through the runway, the pilot has to contact the controller. If there is no aircraft on final approach, the controller gives the 
instruction to cross the runway. It may cause the aircraft at apron $\mathrm{Y}$ to be held for a long time, especially in situations where landing aircraft are frequent.

In Figure 4, the current situation (scenario 1) and the end-around procedures are compared in terms of capacity, average delay and average taxi time. Taxi time is expressed as the time difference between aircraft leave the gate and enter departure queue. Thus, in scenario 1, the amount of the time that the aircraft wait to cross the runway 05 is also included in the average taxi time. In scenario $1 \mathrm{a}$, the average delay time and taxi time reduce by about $73 \%$ and $37 \%$, respectively, while the capacity does not change compared to scenario 1 . On the other hand, the EAT in scenario $1 \mathrm{~b}$ improves capacity, average delay and taxi time about $1.43 \%, 78 \%$ and $52 \%$, respectively.

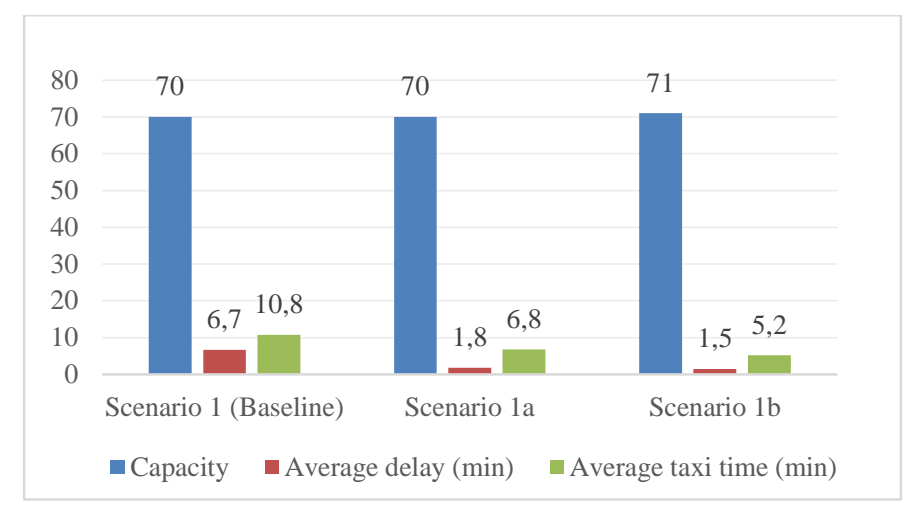

Figure 4. Capacity, average delay and average taxi time of the scenarios

In Figure 5, the delay distribution of the aircraft waiting to cross the runway 05 are given. It is seen that the delay times are very long especially between 15.44 and 16.14. During the simulation, the number of aircraft waiting in the taxiway-1 shown in Figure 2(a) is increased up to 14. The bottleneck in the taxiway has caused a $109 \%$ increase in the overall average delay.

In the figure, it can be noticed that the waiting time of aircraft tends to decrease after 15.65 with the decreasing frequency of arrival operations. In other words, if the arrival traffic is frequent, the aircraft will have to wait a long time to pass the runway, but this period decreases significantly in rare traffic conditions. Hence, the EATs can provide more efficient results at busy airports such as LTBA.

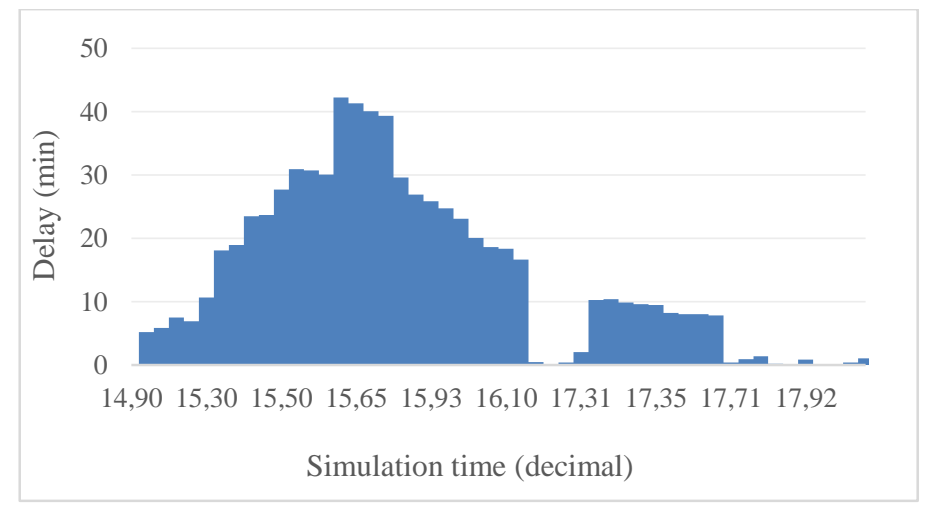

Figure 5. Delay distribution due to aircraft crossings of runway 05 in the baseline scenario 
Figure 6 shows the change of taxi times of aircraft in scenarios 1, 1a and 1b. Taxi times of some aircraft are comparatively high along the simulation time as shown in Figure 6(a), e.g. between 15.18 and 15.64, due to high holding times of the aircraft coming from apron $Y$ to cross the runway 05 . In these periods, the number of aircraft holding to cross the runway increases due to the high frequency of arrival aircraft, which also causes departure aircraft's taxi time to increase.

In scenario 1a, the aircraft at apron Y taxi using the EAT-1. In this case, even though the taxi distance of the aircraft increases their taxi time decreases compared to scenario 1. The taxi distance of EAT-2 is shorter than EAT-1, therefore, it provides more efficient results than scenario 1a. Besides, the difference between the taxi times of the aircraft at apron $\mathrm{Y}$ and at the other aprons has decreased considerably.

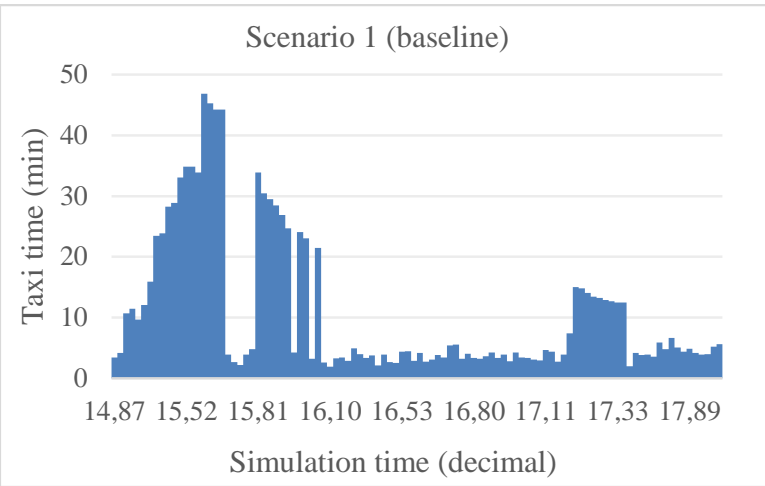

(a)

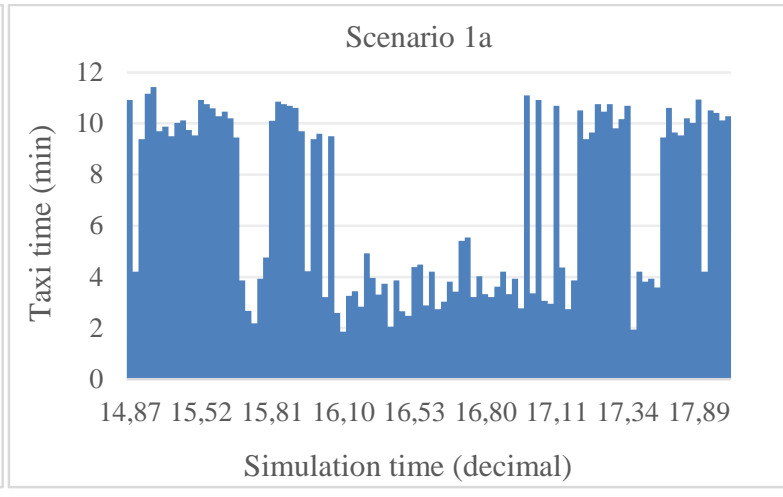

(b)

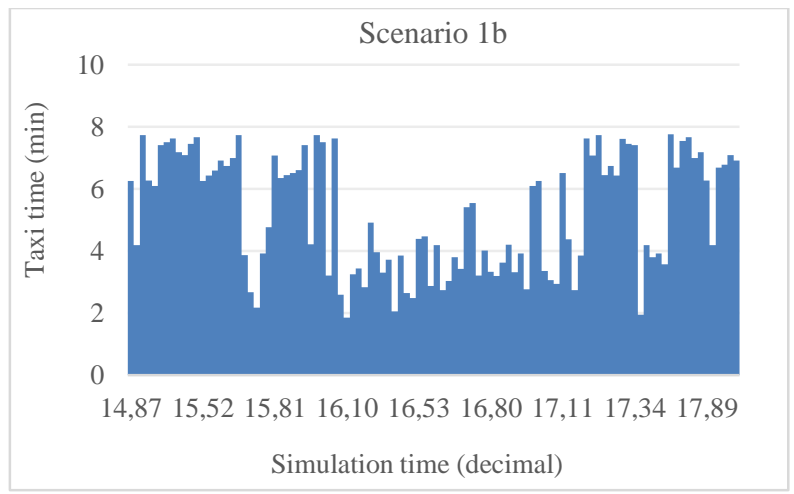

(c)

Figure 6. Departure taxi time distributions for (a) Scenario 1; (b) Scenario 1a; (c) Scenario 1c

Figure 7 shows the effect of the use of the RETs on average runway occupancy times and taxi times for arrival aircraft. There is no difference between 05A-35D and 05A-D and between 23A-17D and 23A-D in terms of the effect of the proposed RETs for runway 05 and 23 as the same flight dataset is used. According to the simulation results, scenario $1 \mathrm{c}$ and $3 \mathrm{a}$ demonstrate that the RET on runway 05 reduces the average runway occupancy time and taxi time by $0.6 \%$ and $0.22 \%$, respectively. In these scenarios, 5.8\% of the aircraft which have the parking positions at apron Y use the new RET, and it is mostly used by heavy aircraft. The use of this proposed taxiway is limited because only $10 \%$ of the flights used in the study is heavy category. Consequently, in the case of an increase in the number of heavy aircraft, the use of the proposed RET can increase. 
On the other hand, scenario $2 \mathrm{a}$ and $4 \mathrm{a}$ show that the RET on runway 23 reduces average runway occupancy time by $10.6 \%$, and $86 \%$ of the aircraft using apron Y also use this proposed RET. In addition, the new RET reduces the average taxi time of arrival aircraft by $9.7 \%$.

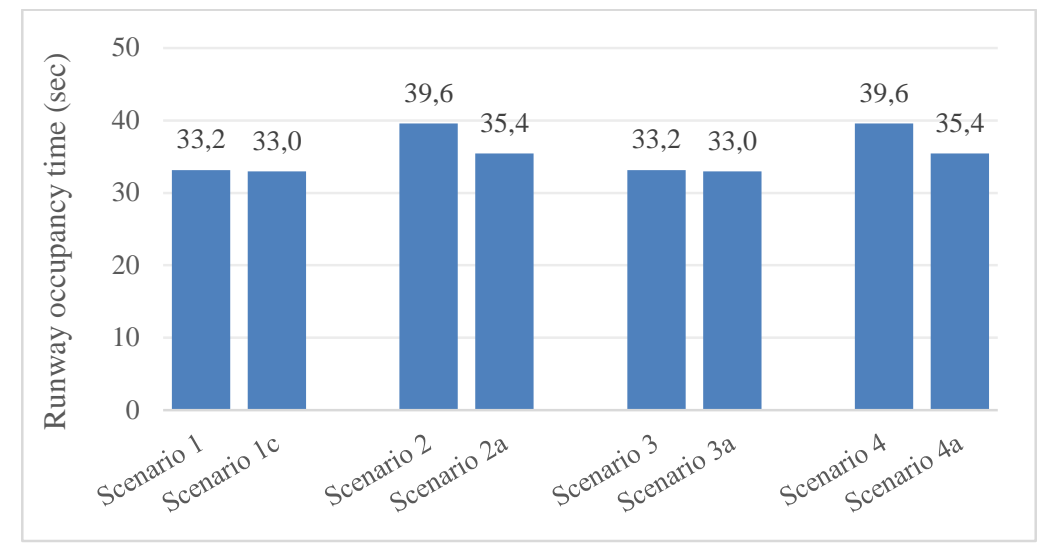

(a)

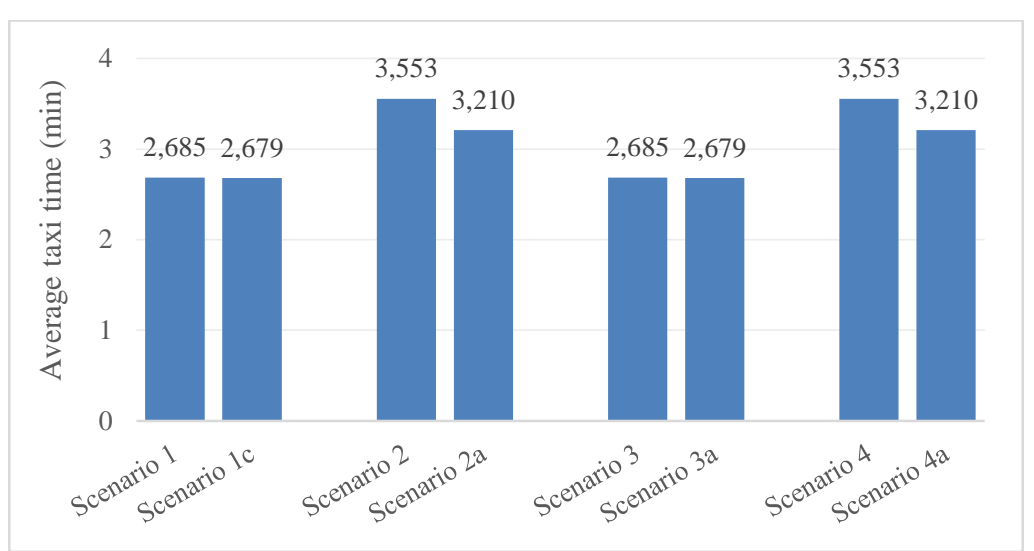

(b)

Figure 7. (a) Average runway occupancy time; (b) average taxi time

\section{DISCUSSION AND CONCLUSIONS}

In this study, the possible benefits of the end-around taxiways (EATs) and rapid-exit taxiways (RETs) on airport capacity and delay are investigated for İstanbul Atatürk Airport (LTBA). The use of EATs can improve safety by preventing aircraft from crossing a runway. It also can reduce the frequency occupancy by reducing controller-pilot communication. Besides, fuel and time savings can be achieved by reducing taxi time, especially at peak hours. RETs, on the other hand, allow aircraft to leave the runway earlier and can provide a more efficient traffic flow by reducing taxi time. It is apparent that increasing their usage can contribute to improve airports' performance when the potential benefits are considered.

As a result of the study, EAT-1 reduces the average delay time and taxi time by about $73 \%$ and $37 \%$ while the EAT-2 reduces average delay and taxi time by about $78 \%$ and $52 \%$, respectively. EAT-2 provides better results compared to EAT-1 due to shorter taxi distance. Besides, it also improves the capacity by $1.43 \%$. The high frequency of arrival aircraft increases the waiting time of the aircraft which will cross the runway 05 since they are required to wait for the arrival aircraft. Therefore, average delay time increases in the absence of an EAT. However, the rate of reduction in average delay and taxi time may reduce in a lower traffic density. 
The RET proposed on runway 23 reduces average runway occupancy time by $10.6 \%$, while the other RET on runway 05 has not made a significant change. It is believed that the reason for this is that the number of aircraft in the heavy category in the flight data set is low, yet the increase in the number of heavy aircraft will increase the use of this taxiway.

Unlike, the existing studies conducted for various parallel runway configurations, this study focused on EAT implementation to an airport with open- $\mathrm{V}$ runway configurationTherefore, the results of this study provide a useful insight for the infrastructural capacity improvements of nearly congested airports having similar runway configuration and demand characteristics. It should also be emphasized that EATs can occupy a very large area in airports. For this reason, their applicability to some airports may not be possible due to existing infrastructure and restricted field available. However, they can be taken into account in constructing new airports.

\section{REFERENCES}

[1] Janic M. Air Transport System Analysis and Modelling: Capacity, Quality of Services and Economics. The Netherlands: Gordon and Breach Science Publishers, 2000.

[2] International Civil Aviation Organization (ICAO). Procedures for Air Navigation Services Air Traffic Management (Doc 4444). 15th ed. Montreal, Canada: ICAO, 2007.

[3] Bazargan M, Fleming K, Subramanian P. A simulation study to investigate runway capacity using TAAM. In: Proceedings of the 2002 Winter Simulation Conference; 8-11 December 2002; San Diego, CA, USA: IEEE. pp. 1235-1243.

[4] European Organization for the Safety of Air Navigation (EUROCONTROL). Airport Capacity Assessment Methodology. 1.1 ed. Brussels, Belgium: EUROCONTROL, 2016.

[5] Wang C, Zhang XY, Xu XH. Simulation study on airfield system capacity analysis using SIMMOD. In: Proceedings of the 2008 International Symposium on Computational Intelligence and Design; 17-18 October 2008; Wuhan, China, China: IEEE. pp. 87-90.

[6] Bubalo B, Daduna JR. Airport capacity and demand calculations by simulation-the case of Berlin-Brandenburg International Airport. Economic Research and Electronic Networking 2011; 12: 161-181.

[7] Guclu OE, Cetek C. Optimization of aircraft taxi movements and gate allocation using hybrid dynamic gate assignment. In: Multidisciplinary Academic Conference; 10-12 May 2013; Prague. pp. 71-79.

[8] Muller C, Santana ESM. Analysis of flight-operating costs and delays: The Sao Paulo terminal maneuvering area. Journal of Air Transport Management 2008; 14: 293-296.

[9] Cetek FA, Cetek C. Simulation modelling of runway capacity for flight training airports. Aeronautical Journal 2014; 118: 143-154.

[10] Odoni AR, Bowman J, Delahaye D, Deyst JJ, Feron E, Hansman RJ, Khan K, Kuchar JK, Pujet N, Simpson Robert W. Existing and Required Modeling Capabilities for Evaluating ATM Systems and Concepts. International Center for Air Transportation Massachusetts Institute of Technology, March 1997. 
Özdemir et al. / Anadolu Univ. J. of Sci. and Technology A - Appl. Sci. and Eng. 19 (1) - 2018

[11] Gao W, Xu X, Diao L, Ding H. SIMMOD based simulation optimization of flight delay cost for multi-airport system. In: International Conference on Intelligent Computation Technology and Automation; 20-22 October 2008; Hunan, China: IEEE. pp. 698-702.

[12] Kleinman NL, Hill SD, Ilenda VA. SPSA/SIMMOD optimization of air traffic delay cost. In: Proceedings of the American Control Conference; 6 June 1997; Albuquerque, USA: IEEE. pp. 4563.

[13] Peng Y, Wei G, Jun-Qing S. Capacity analysis for parallel runway through agent-based simulation. Mathematical Problems in Engineering 2013; 2013: 1-8.

[14] Simaiakis I, Balakrishnan H. Impact of congestion on taxi times, fuel burn, and emissions at major airports. Transportation Research Record 2010; 2184: 22-30.

[15] Lee H, Balakrishnan H. Fast-time simulations of detroit airport operations for evaluating performance in the presence of uncertainties. In: 2012 IEEE/AIAA 31st Digital Avionics Systems Conference (DASC); 14-18 October 2012; Williamsburg, VA: IEEE. pp. 1-13.

[16] General Directorate of State Airports Authority (DHMI). İstatistikler. (Accessed in 19.02.2016), (http://www.dhmi.gov.tr/istatistik.aspx).

[17] European Organization for the Safety of Air Navigation (EUROCONTROL). Network Monthly Operations Report. Brussels, Belgium: EUROCONTROL, 2016.

[18] Ciftci ME, Sevkli M. A new hub and spoke system proposal: A case study for Turkey's aviation industry. Journal of Air Transport Management 2015; 47: 190-198.

[19] Jadhav A, Neogi N, Thaden T. Impact of critical hub airport configuration in the next generation air transportation system. In: Digital Avionics Systems Conference; October 25-29 2009; IEEE. pp. 2.A.3-1-2.A.3-14.

[20] Engelland SA, Ruszkowski LM. Analysis of DFW perimeter taxiway operations. In: 10th AIAA Aviation Technology, Integration, and Operations (ATIO) Conference; 13-15 September 2010; Fort Worth, Texas: AIAA. pp. 1-14.

[21] Uday P, Burder D, Marais KB. Environmental benefits of EAT operations. In 11th AIAA aviation technology, integration, and operations (ATIO) conference; 20-22 September 2011; Virginia Beach, VA: AIAA. pp. 1-18.

[22] Le T, Marais K. Optimization of EAT for efficient operations and environmental benefits. In: Aviation Technology, Integration, and Operations Conference; August 12-14 2013; Los Angeles, CA: AIAA. pp. 1-15.

[23] Federal Aviation Administration (FAA). Airport Design Advisory Circular AC 150/5300-13A, Washington, DC: FAA, 2012.

[24] Mota MM, Scala P, Boosten G. Simulation based capacity analysis for a future airport. In: 2014 Asia-Pacific Conference on Computer Aided System Engineering (APCASE); 10-12 February 2014; South kuta, Indonesia: IEEE. pp. 97-101.

[25] Cetek C, Cinar E, Aybek F, Cavcar A. Capacity and delay analysis for airport manoeuvring areas using simulation. Aircraft Engineering and Aerospace Technology 2014; 86:43-55. 
Özdemir et al. / Anadolu Univ. J. of Sci. and Technology A - Appl. Sci. and Eng. 19 (1) - 2018

[26] Aeronautical Information Publication (IAP). Ataturk airport preferential runway system operations. (Accessed in 26.04.2017), (http://ssd.dhmi.gov.tr/ANSLogin.aspx?mn=41).

[27] NUIC A. User Manual for the Base of Aircraft Data (BADA). Revision 3.5, Eurocontrol Experimental Centre, ECC Note No. 11/03, Brétigny-sur-Orge Cedex, 2003. 